\title{
Virtue ethics in dentistry - a model for developing virtuous dental practitioners
}

SADJ June 2021, Vol. 76 No. 5 p290 - p293

HD Miniggio', PD Motloba², CS Wareham³

\section{INTRODUCTION}

There is a renewed appreciation of the contribution of virtue ethics in clinical healthcare practice, including dentistry. This interest in virtue ethics highlights the limitations of only focusing on the development of clinical skills and competence or mere adherence to a set of ethical rules and guidelines. There is also a growing interest and appreciation that an equally important and integral aspect of dental practice is the development of a virtuous character. From this virtue ethics perspective, a virtue is an excellent trait of character, a disposition, well entrenched in its possessor. ${ }^{1}$

When applied to health care, virtues are those character traits that are important for healthcare practitioners to develop, thereby improving the dental practitioner-patient relationship. In so doing, the healthcare practitioner is able to reciprocate the trust that patients place in the profession. In the context of dental practice, the development and exercise of the virtues of trustworthiness, integrity, discernment, conscientiousness and compassion are considered essential in guiding dental practitioners in their interactions with patients. ${ }^{2}$ A virtuous character develops from continuous practice and from emulating good role models. ${ }^{3}$

In the case of dental practice, one of the sources of role modeling a these virtues would presumably be the clinical supervisors ${ }^{\mathrm{b}}$ who teach dental students during supervised

\section{Author affiliations:}

1. Hilde D Miniggio: BDS (UMF, Cluj-Napoca), MScMed (Bioethics and Health Law) (Wits), PGDip (Health Sciences Education) Wits), Senior Lecturer, Department of Oral \& Maxillofacial Pathology, Oral Microbiology \& Oral Biology, Sefako Makgatho Health Sciences University, South Africa.

ORCID Number: 0000-0003-2003-0306

2. Pagollang D Motloba: BDS, MPH (Epid), MDent (Comm. Dent), $M B L$, Head, Department of Community Dentistry, School of Oral Health Sciences, Sefako Makgatho Health Sciences University, South Africa.

ORCID Number: 0000-0003-1379-7576

3. Christopher S Wareham: BA Hons (Rhodes), MA (Rhodes), PhD (Milan), Associate Professor, Steve Biko Centre for Bioethics, School of Clinical Medicine, Faculty of Health Sciences, University of the Witwatersrand, South Africa. ORCID Number: 0000-0003-1631-8868

Corresponding author: Pagollang D Motloba

Department of Community Dentistry, School of Oral Health Sciences,

Sefako Makgatho Health Sciences University, South Africa.

Email: pagollang.motloba@smu.ac.za

Author contributions:

1. Hilde D Miniggio: Conceptualization, first draft, revision, final writeup and final approval - $65 \%$

2. Pagollang D Motloba: First draft, revision, final write-up and final approval - $25 \%$

3. Christopher S Wareham: First draft, revision, final write-up and final approval - $10 \%$ dental treatment and interaction with the patient at the chair-side. Although great strides have recently been made in identifying the clinical competencies and qualities which are required for effective clinical teaching, these qualities are discussed in the literature in a fragmented fashion under the umbrella of professionalism in dental practice. ${ }^{3}$ Further to this, evidence suggests that "clinicians often occupy a clinical teaching role without being adequately prepared for or orientated to the associated demands". ${ }^{4-7}$ Given the significance of this source of role modeling in shaping the moral character of future dental practitioners, it is surprising that the virtues that clinical supervisors should develop and routinely demonstrate during dental chair-side teaching and patient interaction are not directly addressed in current literature.

In this article we propose a preliminary model for understanding and incorporating virtues as part of the development of the moral character of the dental practitioner drawing on Aristotelian virtue ethics. We firstly provide a brief overview of Aristotelian virtue ethics and the development of a virtuous character and then describe how Aristotle's virtue ethics can be integrated in dental chair-side teaching. To this end, we propose an interactive model with the following conceptual propositions:

(i). Virtues can be taught by role modeling as part of the authentic patient-dental student-clinical supervisor interaction during clinical teaching at the chair-side.

(ii). Clinical supervisors are in an ideal position in their dual function of dental practitioner and teacher in this reallife clinical scenario, thus are able to play a critical role in the development of character during chair-side dental training.

(iii). Through this relationship, clinical supervisors can inspire and shape the development of a virtuous character in future dental practitioners by enacting these virtues in every interaction with the student and patient, respectively.

(iv). The refinement of these virtues will conceivably continue beyond in routine dental practice.

\footnotetext{
a In this context a role model is one that "demonstrates a standard of excellence which should be imitated". ${ }^{9}$

b "Clinical supervision in the context of dental training can be defined as the monitoring, guidance and feedback on matters of personal, professional and educational development in the context of patient care". ${ }^{9}$
} 
The discussion in this paper is confined to the role of virtues in the patient-dental student-supervising clinician relationship while acknowledging that these virtues may be equally valuable for teachers in the non-clinical dental subjects.

In the sections to follow, we provide a brief overview of how Aristotle's virtue ethics can be integrated in the dental chair-side teaching. We do so by first conceptualizing virtues and then exploring how virtues can be instilled as part of the patient-dental student-supervising clinician relationship.

The role of virtue in the development of a virtuous character

We begin by exploring Aristotelian virtue ethics and the development of a virtuous character. Virtue ethics is an ethical theory that is primarily concerned with the development of a virtuous character which is considered an essential ingredient in living a good life. For Aristotle, who is considered the founding father of virtue ethics, a good life represents a "condition of human flourishing" known as eudaimoniac. ${ }^{3}$ Aristotle is of the view that noone can live a happy and fulfilled life, unless they possess and exercise certain moral virtues. A moral virtue can be defined as an "acquired habit or disposition to do what is morally right or praiseworthy". ${ }^{8}$

Such a virtue or character trait is desirable for its own sake and can be identified in the balance of two extremes, one of deficiency and one of excess; both such imbalances impact negatively on the virtue. Let us consider the virtue of compassion which is considered essential in healthcare practice as case in point to illustrate Aristotle's concept of the 'golden mean'.

Compassion refers to "an active regard for another's welfare with an imaginative awareness and emotional response of deep sympathy, tenderness and discomfort at another's misfortune or suffering". ${ }^{10}$ Compassion is the virtue that is achieved through the appropriate balance of two extremes; a deficiency in compassion leads to callous attitude while an excess in compassion leads to an overly compassionate or pitying attitude, both of which would not be desirable in the context of healthcare provision.

The question then arises; how does one ensure that the right balance is achieved between the two extremes in particular scenarios encountered in healthcare provision? The answer to this question lies in the correct application of what Aristotle deems to be the dominant virtue through which all other virtues are balanced, namely phronesis or practical wisdom. ${ }^{3}$ Practical wisdom requires that a careful and insightful choice is made in the "proper order of priority and to make the right and good decision in the most difficult situation". ${ }^{11}$ Such wisdom equips individuals with the insight necessary to differentiate right from wrong, based on the context of a particular situation. ${ }^{12}$

c "Eudaimonia is happiness, contentment, and fulfillment; it's the name of the best kind of life, which is an end in itself and means to live and fare well". ${ }^{13}$
As with all other virtues, practical wisdom can be learnt through practice as Horn explains: "every time one is faced with a new situation that requires moral deliberation and choice, the virtue of practical wisdom is strengthened". ${ }^{14}$

The aim of virtue ethics is then to attain excellence in moral character which in turn is achieved by practicing good habits through good teaching and continuous practice. Further to this, "a virtuous person reaches a level of internal harmony or integration between cognition and emotion, freedom and adherence to ideals, and individuality and community". ${ }^{12}$ In order for individuals to achieve a virtuous character they need to develop and continuously exercise the following habits:

- "recognize or perceive moral situations correctly (to be sensitive to what is at stake in a situation)";

- "respond emotionally to the situation in the right way (this may include being dispassionate in the right circumstances)";

- "think well about what to do in the situation (either to know how to act or to reason appropriately about how to act)" and;

- "be motivated strongly enough to carry the right action through". ${ }^{15,16}$

Having considered the role of virtue in the development of a virtuous character, in the next section we propose a model for understanding and incorporating virtues as part of the development of the moral character of the dental practitioner in the patient-dental studentsupervising clinician relationship.

\section{Virtues in action during dental chair-side teaching}

The training of healthcare practitioners, including dental practitioners places great emphasis on "the objective and quantifiable science and clinical practice, which at time cripples the patient-physician relationship". ${ }^{12}$ In the dental clinical context, research suggests that "clinical performance of students was positively correlated with proficiency in moral reasoning" and that "moral reasoning could be improved through classes in medical ethics and small-group discussion of ethical issues, based on actual clinical scenarios". ${ }^{15}$

Interestingly it has been shown that "there are strong similarities between wise ethical judgement in medicine and what we would ordinarily call 'clinical judgement'". ${ }^{16,17}$ Both clinical judgement and ethical judgement "requires repetitive and supervised practice over years of training so that the trainees can learn a skill that comes by experience". ${ }^{17}$

A virtue ethics approach focuses on such practical wisdom and good clinical judgement. ${ }^{16}$ Specific "kinds of human activities elicit specific virtues, which Aristotle described as 'states of character'" 3,12 Individuals who role model the ideal character traits and the "ideal performance for such activities serve as a standard by which to judge performance and a template on which to model one's own actions". 12 
We propose a preliminary virtue-based model in which the clinical supervisor represents one of the sources of role-modeling virtues within the authentic real-life clinical interaction between the patient, dental student and the supervising clinician during the chair-side teaching ex perience. From such a perspective, clinical supervisors convey not only clinical skills, experience and subject knowledge during this real-life experience, but also practical wisdom as they guide students as to "how best to negotiate the clinical encounter". ${ }^{12}$

"In doing so, students can recognize and appreciate how virtue can help to provide the best possible clinical decision and action". ${ }^{2}$ Further to this, chair-side teaching is relational and is "integral and constitutive of the teaching relationship and role modeling is a powerful strategy by which character development can be instilled". ${ }^{18}$ This implies that certain character traits would be expected from the clinical supervisors in their interaction with dental students and patients, respectively. In the model that we propose, the supervising clinician would:

i. exhibit a "strong internal sense of appropriate and good behaviors, based on a robust set on inbuilt values and virtues". ${ }^{16}$

ii. role model the virtues of trustworthiness, integrity, conscientiousness, discernment and compassion towards the patient during chair-side teaching thereby inspiring dental students to develop these virtues.

iii. express the virtues of honesty, fairness, compassion and patience towards dental students in the chair-side interaction and in this way support and shape the development of their individual moral character.

iv. offer support and guidance to students (and colleagues) who fail to display the expected excellence in character during this patient interaction. ${ }^{16}$

v. role model these virtues as a way of advancing the goals of dental practice at every clinical encounter, namely "the good of the patient in relation to promoting, maintaining and restoring oral health". ${ }^{1}$

In sum, a virtuous clinical supervisor is one who shows compassion and active regard to the well-being of the patient and the student in her interaction in the patientdental student-supervising clinician relationship at the chair-side. Further to this, she builds trust with the patient by meaningful collaborations and by taking time to understand the oral healthcare needs of each patient. She is also fair towards the student and honest with the patient. She responds sensitively to the specific situation and displays wise judgment during her interactions in the patient-dental student-supervising clinician relationship.

Such a virtuous clinical supervisor is more likely to inspire, motivate and create the foundation upon which dental students can develop their own character by first emulating that which she role models. In cases in which students deviate from such standards of excellence modeled by the clinical supervisor, which is likely occur from time to time, a virtuous clinical supervisor would empa- thetically and patiently guide the student in understanding where they went wrong and advising on ways to correct such deviations. ${ }^{16}$ In this way, the development and continued exercise of these virtues is ensured in the patient-dental student-supervising clinician relationship, thereby encouraging insightful practical wisdom in the clinical decision making process and ensuring that the good of the patient in relation to promoting, maintaining and restoring oral health is fulfilled.

Nevertheless, it could be argued that one cannot in fact expect that clinical supervisors should develop and model specific character traits and that even an intolerant, insincere, indifferent and unfair clinical supervisor could nonetheless still oversee the procedural technical correctness of a class II cavity preparation or an extraction that the student is required to perform.

Whilst this might be so by a very small margin, it is unlikely that a supervising clinician with such character traits could motivate, inspire and assist the student in developing their individual, internally motivated virtuous character. This is because teaching at the chair-side is relational, such an activity "demands the participation of both teacher and learner, so the character of the teacher is part of the puzzle of what makes a moral and ethical teacher". ${ }^{18}$ Further to this "teaching as professional work requires constant practical judgement to ensure that the moral requirements of everyday practice are met". 18 "Medical education is not simply about conveying knowledge; it is also concerned with transformation in nurturing the character of the good doctor".?

\section{CONCLUSION}

In this article we proposed a preliminary virtue ethics model for understanding and incorporating virtues as part of the development and shaping of the moral character of the dental practitioner; this may enhance dental chair-side training and education strategies and in this way promote excellence in dental training and beyond in routine dental practice. In our proposed model, virtues are taught by role modeling as part of the authentic patient-dental student-clinical supervisor interaction during clinical teaching at the chair-side.

To this end we showed how through this relationship, clinical supervisors can inspire and shape the development of a virtuous character in future dental practitioners and that the development of a virtuous character in future dental practitioners should not be overshadowed by clinical skills and subject knowledge during chair-side teaching. Clinical supervisors should further be empowered and encouraged to use a virtue model "as a touchstone for accomplishing their goals in training students" and achieving excellence in clinical teaching. ${ }^{12}$

There is great scope for further empirical research in this field which could investigate the various pedagogical strategies which Dental Schools could develop to ensure that character development is adequately addressed and incorporated in dental chair-side teaching. This would be an important initiative in addressing virtues of future dental practitioners at its source, "for not to teach virtues, is to leave the door open for vices". ${ }^{12}$ 


\section{References}

1. Hursthouse, R. The Virtues Benefit Their Possessor. 2001. DOI:10.1093/0199247994.003.0009. Availableat:https://plato. stanford.edu/entries/ethics-virtue/. Accessed 16/05/2021.

2. Miniggio HD, Motloba PD, Wareham CS. The renaissance of virtue ethics and its application in dentistry. S Afr Dent J. 2020; 75(6): 332-6.

3. Aristotle. The ethics of Aristotle: The Nichomachean ethics. Harmondsworth: Penguin. 1976.

4. Maart R, Gordon N. Dental clinical teachers' perceptions of their teaching role. S Afr Dent J. 2018; 73(4): 304-8.

5. Singh S, Pai DP, Sinhal NK, Kaur A, Kyaw Soe HH, Barua A. Qualities of an effective teacher: what do medical teachers think? BMC Med Ed. 2013; 13: 128.

6. Polyzois I, McLoughlin J, Kelly A, Claffey N. Clinical teaching in restorative dentistry and the variation between students' and supervisors' perceptions of its effectiveness. Eur $\mathrm{J}$ of Dent Educ. 2010; 14: 92-8.

7. Irby DM. What clinical teachers in medicine need to know? Acad Med. 1994;69(5):333-42.

8. Beauchamp T, Childress J. Principles of biomedical ethics, $2^{\text {nd }}$ ed. New York: oxford University Press, 1983.

9. Kilminster SM, Cottrell D, Grant J, Jolly B. AMEE Guide No. 27: Effective educational and clinical supervision. Med Teach. 2007; 29: 2-19.

10. Beauchamp T, Childress J. Principles of biomedical ethics, $6^{\text {th }}$ ed, New York: Oxford University Press, 2008.

11. Pellegrino ED. Professionalism, profession and the virtues of the good physician. Mt Sinai J Med. 2002; 69(6): 378-84.

12. Shah N, Marcum JA. Can Virtues be taught in medicine? Aristotle's Virtue Theory and Medical Education and Clinical Practice. Mirab Med 4. 2015: 10-22.

13. Athanassoulis N. Virtue Ethics. Internet Encyclopedia of PhiIosophy. Available at: https://iep.utm.edu/virtue/. Accessed 18/05/2021.

14. Horn L. Virtue ethics in the development of a framework for public health policy making [dissertation]. University of Cape Town. 2010. DOI:10.13140/RG.2.1.3255.4323. Available at: https://www.semanticscholar.org/paper. Accessed: 15/05/ 2021.

15. Curren S, Cruess R, Steiner Y. Role Modelling- Making the Most of a Powerful Teaching Strategy. Theory Res Ed. 2014; 2(3): 266-82.

16. Arthur J, Thoma H, Ignatowicz A, Kristjansson K, Kotzee B, Qiu T. Virtuous Medical Practice. 2015. The Jubilee Centre for Character and Virtues.

17. Kaldjian LC. Teaching Practical Wisdom in Medicine Through Clinical Judgment. J Med Ethics. 2010; 36(9): 558-62.

18. Cooke, S. The Moral Work of Teaching: A Virtue-Ethics Approach to Teacher Education. In The SAGE handbook of research on teacher education. The SAGE Handbook of Research on Teacher Education. SAGE Publications Ltd. 2017; 2: 419-34. 